Article

\title{
Study on the Properties and Process Parameters of Different Clays in Disc Granulation
}

\author{
Hui Li ${ }^{1,2, *}$, Jingjie Zhang ${ }^{1}$, Wukui Zheng ${ }^{1}$, Tian Cui ${ }^{1}$ and Yuxuan Yang ${ }^{1}$ \\ 1 College of Materials Science and Engineering, Xi'an University of Architecture and Technology, Xi'an 710055, \\ Shaanxi, China; 15388618192@163.com (J.Z.); zheng.wukui@xauat.edu.cn (W.Z.); ctbryant@126.com (T.C.); \\ yyx9202@163.com (Y.Y.) \\ 2 Shaanxi Ecological Cement \& Concrete Engineering Technology Research Center, Xi'an 710055, Shaanxi, China \\ * Correspondence: clxylihui@xauat.edu.cn
}

Received: 16 February 2020; Accepted: 2 April 2020; Published: 6 April 2020

check for updates

\begin{abstract}
Sintering solidification is an effective way to treat soil contaminated with nonvolatile heavy metal. The ceramsite prepared from contaminated soil after sintering can be used as lightweight aggregate in concrete. The preparation process of ceramsite can be divided into two steps: granulation and sintering. As one of the key processes, granulation is directly related to the final solidification and physical properties of ceramsite, and the properties of the clay are directly related to the granulation process. In this work, clays from different regions granulated with disc granulation were studied and compared. The results showed that different clays had significantly different performances in granulation with the same granulation system, and each clay had its own best process parameter. The significance analysis showed that the volume surface mean diameter and the reduction ratio had the most significant impact on the granulated fraction among all the factors. No matter which process parameter was used, as the particle size increased, the granulated fraction increased first and then decreased, and the best results were obtained when the average volume diameter was about $20.5 \mu \mathrm{m}$. Furthermore, as the reduction ratio increased, the granulated fraction decreased. These two factors are easy to measure and can be used for predicting the granulation effect of different clays, which can further guide industrial production.
\end{abstract}

Keywords: clay; disk granulation; granulated fraction; particle size; lightweight aggregate; ceramsite

\section{Introduction}

Heavy metal pollution is a serious problem in contaminated soil [1], and the polluted soil needs to be properly repaired before it can be reused. There are many possible methods of remediation, including physical remediation [2,3], chemical remediation [4,5], and biological remediation [6-9]. No matter what technology is used, the basic concept is to remove heavy metals from the soil or to reduce the biological toxicity and migration of heavy metals in the soil. Sintering solidification is one of the most effective ways to treat soil contaminated with nonvolatile heavy metal. At high temperatures, the heavy metal elements form new stable crystals or are immobilized in lattices [10,11]. Moreover, the ceramsite prepared after clay sintering can be used as lightweight aggregate in concrete [12], which can further solidify heavy metals.

The preparation of ceramsite by sintering can be divided into two steps: granulation and sintering. As one of the key processes, granulation is directly related to the final solidification and physical properties of ceramsite, and the properties of the clay are directly related to the granulation process. Clays that come from different regions and environments have huge differences in mineral composition, physical properties, and so on [13-17]. Thus, the granulation process of different clays may be very different. Although there has been some research about granulation, such as research on the process 
parameters of disc granulation [18-22], it differs between different granulation processes or even the mechanism of granulation [23-26]. There have been few studies on the influence of different clays on granulation.

In this work, clays from different regions in China were studied with the disc granulation system. By testing their granulation effect, the process parameter for each clay was analyzed. The comparison of different clays in disc granulation was also studied. Finally, a significance analysis was used to determine which factors heavily affect the granulation process. The details are shown below.

\section{Experiment}

\subsection{Raw Materials and Equipment}

Eight different clays from different parts of China were collected for the experiment. Their chemical composition was analyzed by X-ray fluorescence method (XRF, Bruker, Karlsruhe, Germany), and the results are listed in Table 1 . Their mineral phase composition was analyzed by X-ray diffraction (XRD, Rigaku Corporation, Tokyo, Japan), as shown in Figure 1.

Table 1. Chemical composition of different clays (wt.\%).

\begin{tabular}{|c|c|c|c|c|c|c|c|c|c|}
\hline Clay & $\mathrm{Na}_{2} \mathrm{O}$ & $\mathrm{MgO}$ & $\mathrm{Al}_{2} \mathrm{O}_{3}$ & $\mathrm{SiO}_{2}$ & $\mathrm{~K}_{2} \mathrm{O}$ & $\mathrm{CaO}$ & $\mathrm{TiO}_{2}$ & $\mathrm{Fe}_{2} \mathrm{O}_{3}$ & Other \\
\hline $\begin{array}{c}\text { C1 } \\
\text { (Xi'an Huxian) }\end{array}$ & 1.42 & 2.27 & 17.52 & 62.61 & 3.30 & 1.70 & 0.82 & 6.72 & 3.63 \\
\hline $\begin{array}{c}\mathrm{C2} \\
\text { (Xi'an Jingyang) } \\
\text { C3 }\end{array}$ & 0.89 & 3.32 & 12.59 & 46.50 & 2.46 & 22.78 & 0.72 & 5.71 & 5.05 \\
\hline $\begin{array}{c}\text { (Shaanxi } \\
\text { Hanzhong) }\end{array}$ & 1.04 & 2.03 & 18.51 & 63.04 & 3.28 & 1.39 & 0.83 & 7.11 & 2.79 \\
\hline $\begin{array}{c}\text { C4 } \\
\text { (Neimenggu } \\
\text { Baotou) }\end{array}$ & 2.27 & 2.31 & 13.74 & 60.17 & 2.87 & 8.44 & 0.63 & 5.42 & 4.14 \\
\hline $\begin{array}{c}\text { C5 } \\
\text { (Shandong } \\
\text { Zoucheng) }\end{array}$ & 2.14 & 1.52 & 15.93 & 65.89 & 2.68 & 1.87 & 0.76 & 5.33 & 3.88 \\
\hline $\begin{array}{c}\text { C6 } \\
\text { (Sichuan } \\
\text { Luzhou) }\end{array}$ & 1.93 & 1.32 & 13.09 & 66.48 & 2.43 & 2.05 & 0.91 & 7.99 & 3.81 \\
\hline $\begin{array}{c}\text { C7 } \\
\text { (Heilongjiang } \\
\text { Mohe) }\end{array}$ & 1.75 & 1.13 & 18.04 & 60.89 & 2.85 & 1.83 & 1.15 & 8.20 & 4.17 \\
\hline $\begin{array}{c}\text { C8 } \\
\text { (Henan } \\
\text { Sanmenxia) }\end{array}$ & 1.44 & 2.66 & 14.00 & 58.38 & 2.85 & 10.10 & 0.75 & 5.53 & 4.30 \\
\hline
\end{tabular}




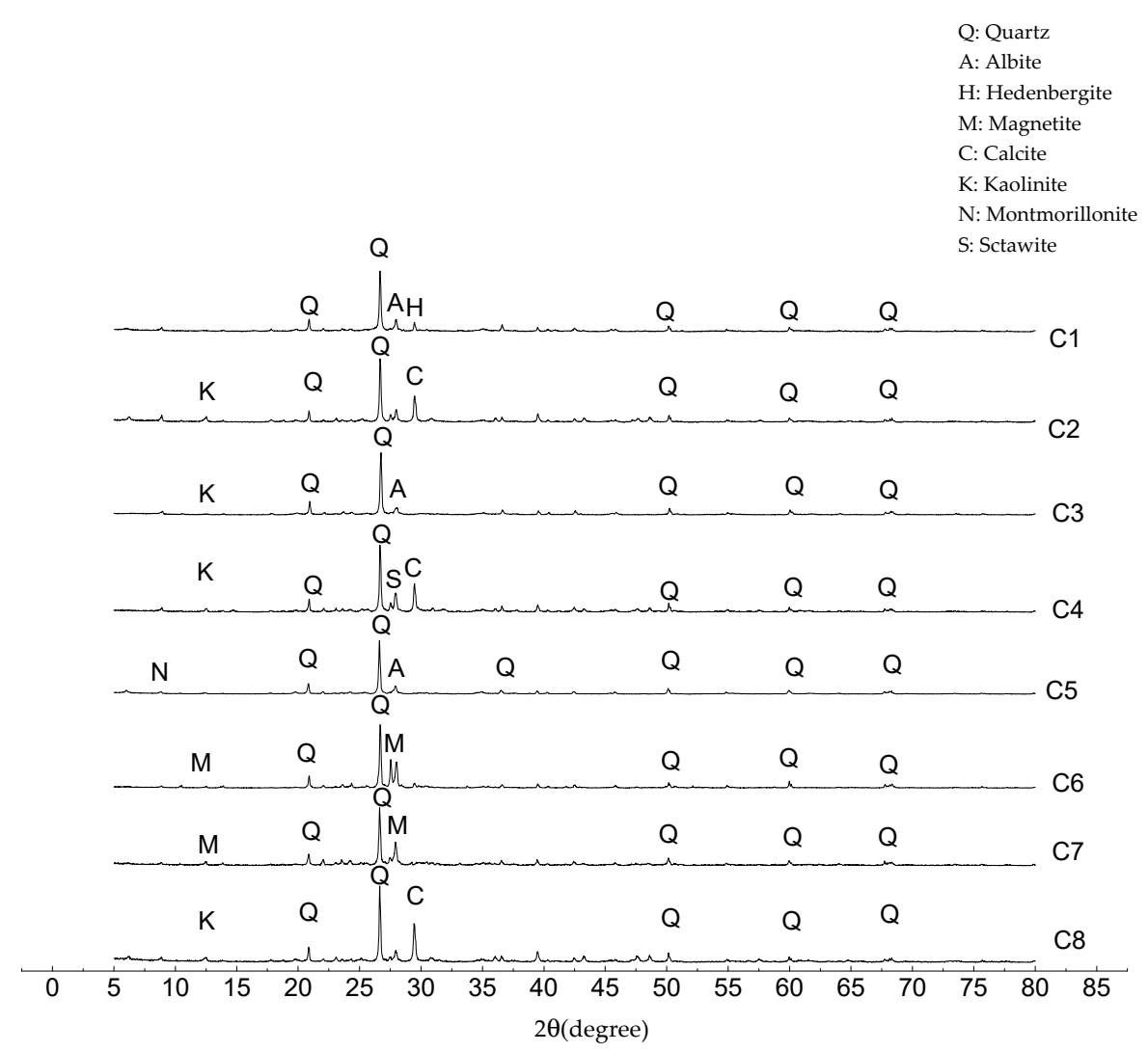

Figure 1. Mineralogical composition of different clays.

Clays were collected in small blocks. Prior to use, they were put into the oven for $24 \mathrm{~h}$ at $105^{\circ} \mathrm{C}$ (until the water content was lower than $0.5 \mathrm{wt} . \%$ ) and then ground in a ball mill for $30 \mathrm{~min}$. Finally, the samples were ready for granulation. The size distribution and volume surface mean diameter (VMD) of the different clays are shown in Table 2.

Table 2. The size distribution of different clays.

\begin{tabular}{ccccc}
\hline Clay & VMD/ $\boldsymbol{\mu m}$ & $\mathbf{d}_{\mathbf{1 0}} / \boldsymbol{\mu m}$ & $\mathbf{d}_{\mathbf{5 0}} / \boldsymbol{\mu m}$ & $\mathbf{d}_{\mathbf{9 0}} / \boldsymbol{\mu m}$ \\
\hline C1 & 16.04 & 1.29 & 7.84 & 42.59 \\
C2 & 12.87 & 1.09 & 5.39 & 35.43 \\
C3 & 11.73 & 1.09 & 5.10 & 32.86 \\
C4 & 35.08 & 1.78 & 23.90 & 85.81 \\
C5 & 22.01 & 1.52 & 12.93 & 56.75 \\
C6 & 23.65 & 1.43 & 11.26 & 67.45 \\
C7 & 16.69 & 1.36 & 8.02 & 45.42 \\
C8 & 18.73 & 1.34 & 10.58 & 48.25 \\
\hline
\end{tabular}

The apparent density, tap density, and reduction ratio of the different clays are shown in Table 3. Apparent density and tap density were measured by the powder comprehensive performance tester. (The mineral composition, angle of repose, and collapse angle did not significantly influence the granulation process of clay, and they are therefore not discussed in this paper.) 
Table 3. The apparent density, tap density, and reduction ratio of different clays.

\begin{tabular}{cccc}
\hline Clay & Apparent Density $(\mathrm{g} / \mathrm{mL})$ & Tap Density $(\mathrm{g} / \mathrm{mL})$ & Reduction Ratio/\% \\
\hline C1 & 0.781 & 1.390 & 43.81 \\
C2 & 0.750 & 1.363 & 44.89 \\
C3 & 0.734 & 1.332 & 44.97 \\
C4 & 0.898 & 1.666 & 46.10 \\
C5 & 0.767 & 1.370 & 44.01 \\
C6 & 0.829 & 1.482 & 44.06 \\
C7 & 0.691 & 1.283 & 44.14 \\
C8 & 0.825 & 1.483 & 44.36 \\
\hline
\end{tabular}

The equipment used in the experiment is shown in Table 4. The water used for granulation was tap water.

Table 4. The equipment used in the experiment.

\begin{tabular}{ccc}
\hline Equipment & Model & Company \\
\hline XRF & S4 PIONEER & Brook AXS, Germany \\
Powder comprehensive performance tester & BT-1000 & Dandong Baite Instrument Co. Ltd \\
Laser particle sizer & HELOS/BR/OM/RODOS/T4-R4 & Changsha Instrument Factory \\
Drying oven & FN101-A & Shenyang North Instrument Factory \\
ball mill & \$300 $\times 300$ & Chuzhou Huaye Electromechanical Company \\
Disc pelletizer & QLC400-II & Chuzhou Huaye Electromechanical Company \\
\hline Fully automatic sprinkler & GPY-01
\end{tabular}

\subsection{Experimental Procedures and Method}

In order to reduce the influence of human factors on the experiment and to reduce experimental error, an automatic spray and granulation system was used, as shown in Figure 2.

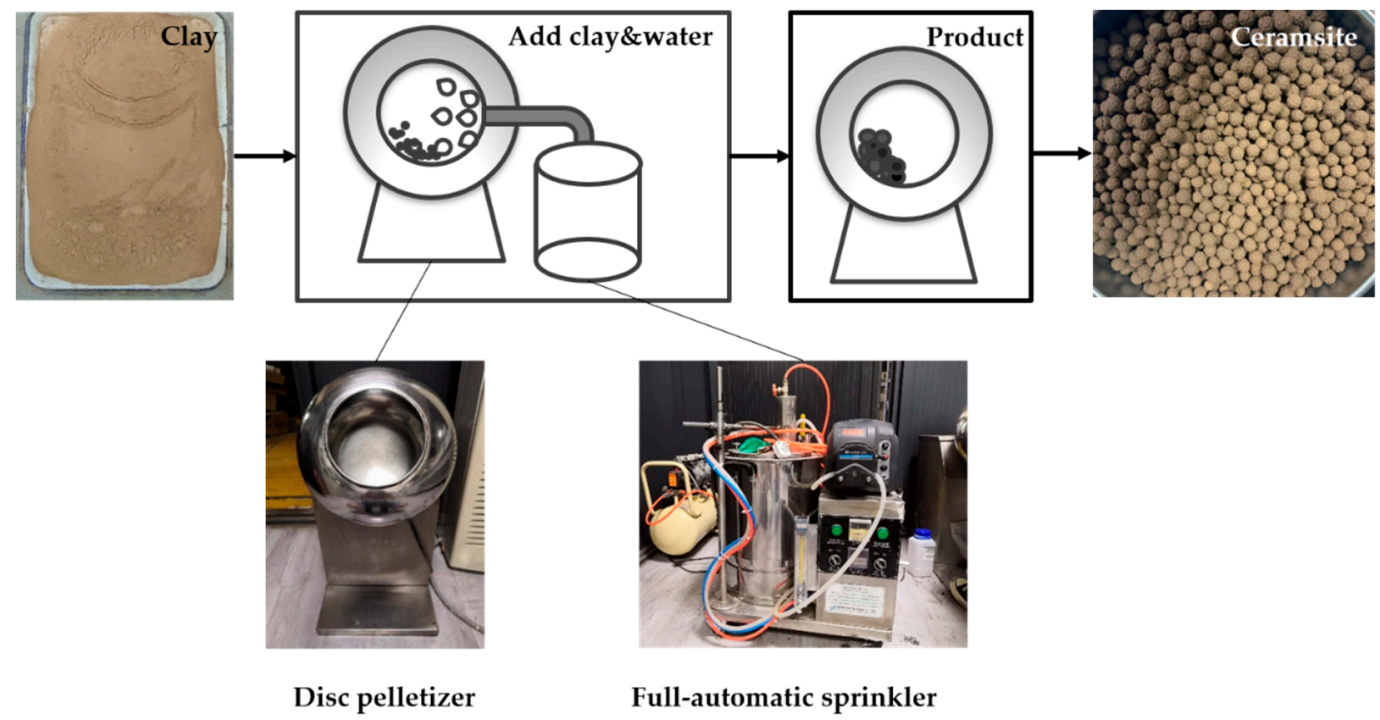

Figure 2. The experimental system.

For each experiment, $1 \mathrm{~kg}$ of clay was used. The granulation time was set as $15 \mathrm{~min}$, and the corresponding amount of water addition was controlled by setting the sprinkling time and the interval time of the sprinkler. The number of times soil materials were added equaled the number of times water was sprayed, and the amount of each addition could be calculated.

At the beginning of the experiment, the disc granulator was turned on, and the speed was set. Clay was added into the rotating disc, the position of the sprinkler was adjusted to the same place in each experiment and aligned to the upper position of the soil center, and it was then turned on to start 
the granulation. After $15 \mathrm{~min}$, the sprinkler was turned off, the rotational speed of the disc granulator was turned down, and the ball was then removed with a spoon at a low rotational speed.

The main factors that influence disc granulation are the inclination angle of the disc, the amount of water added, and the rotational speed. The most suitable disc inclination is related to the diameter of the disc, that is, the disc inclination decreases with an increase in the diameter of the disc [25]. Previous experiments have shown that the granulator used in this experiment achieves the best result when the inclination angle is $55^{\circ}$. Therefore, the disc inclination angle was fixed to $55^{\circ}$. Previous experiments have also shown that the water content should be controlled in the range of $10-25 \%$. It is difficult to make balls with clay containing too little water, while powders with too much water can easily become slurry. Based on previous experiments, the rotational speed was set between 41 and $49 \mathrm{r} / \mathrm{min}$.

In this experiment, five kinds of clay ( $\mathrm{C} 1-\mathrm{C} 5)$ were used, and three kinds $(\mathrm{C} 6-\mathrm{C} 8)$ were used to verify the conclusion. The influence of disc inclination, water content, and disc speed were studied according to the parameters outlined in Table 5. Each experiment with the same parameters was carried out 3 times to verify the reproducibility of the system.

Table 5. The experimental method.

\begin{tabular}{|c|c|c|c|c|c|c|}
\hline Experimental Method & Parameters & $\mathrm{C} 1$ & $\mathrm{C} 2$ & $\mathrm{C} 3$ & $\mathrm{C} 4$ & $\mathrm{C} 5$ \\
\hline \multirow{3}{*}{$\begin{array}{l}\text { Testing of different } \\
\text { water addition }\end{array}$} & Inclination (degrees) & & & 55 & & \\
\hline & Rotation speed $(\mathrm{r} / \mathrm{min})$ & & & 45 & & \\
\hline & Water addition $(\%)$ & & & $13,16,19,22$ & & \\
\hline \multirow{3}{*}{$\begin{array}{l}\text { Testing of different } \\
\text { rotation speeds }\end{array}$} & Inclination (degrees) & & & 55 & & \\
\hline & Water addition $(\%)$ & & & 13 & & \\
\hline & Rotation speed (r/min) & & & $41,45,47,49$ & & \\
\hline
\end{tabular}

\subsection{Testing Methods}

The granulated fraction was used in the analysis as it reflects the difficulty of granulation, and it was calculated by the following equation:

$$
\text { Granulated fraction }=\frac{\text { The amount of round ball bigger than } 0.9 \mathrm{~mm}}{\text { The amount of raw material }+ \text { water added }}
$$

The ball size distribution was measured by screening the ball with 3, 5, 7, and 16 mesh serial sleeves. Then, the mass of different particle sizes was weighed. As this work studied the properties of different clays in the preparation of ceramsite, whether or not the particles could reach the requirement of ceramsite used as lightweight aggregate was considered the key index of granulation according to the National Standard of the People's Republic of China "GB/T 17431.1-2010 Lightweight aggregates and its test methods-Part 1: lightweight aggregates".

Significance analysis was carried out by SPSS®(Statistical Product and Service Solutions) software (IBM, Armonk, New York, The United States) for the properties of the different clays and the granulated fraction of each granulation process.

\section{Results and Discussion}

In this experiment, it was clearly seen that all five clays from different regions could easily form balls, but the appearance and particle size distribution were significantly different. With the same process parameter, the product could form uniform balls or balls with large size distributions, as shown in Figure 3. Furthermore, with the same clay, the process had a totally different influence on the granulation results, as shown in Figure 4. Therefore, it is important to study the granulation rules of different clays and determine which factors have the greatest influence on the granulation process. 


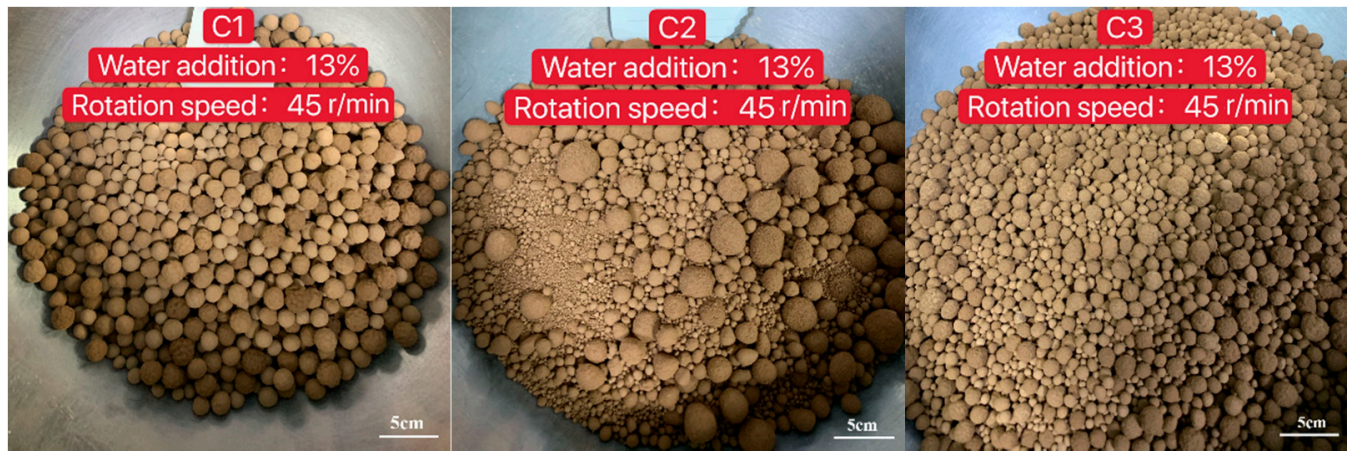

Figure 3. Granulation between different clays with the same process parameter.

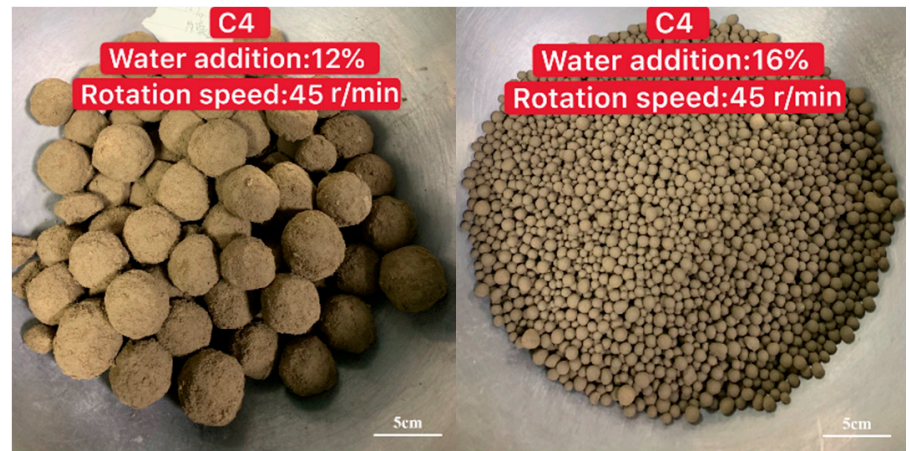

Figure 4. Granulation of different process parameters with the same clay.

\subsection{The Influence of Water Addition and Rotation Speed on the Granulation of Different Clays}

The influence of water addition on the granulated fraction was studied, as shown in Figure 5. For C4, when the water addition was higher than $16 \%$, the clay turned into slurry, which could not be used for granulation. Therefore, there were only two sets of data for C4. Based on this, $12 \%$ water addition was tested for $\mathrm{C} 4$ in order to have more data for the analyzability of the results.

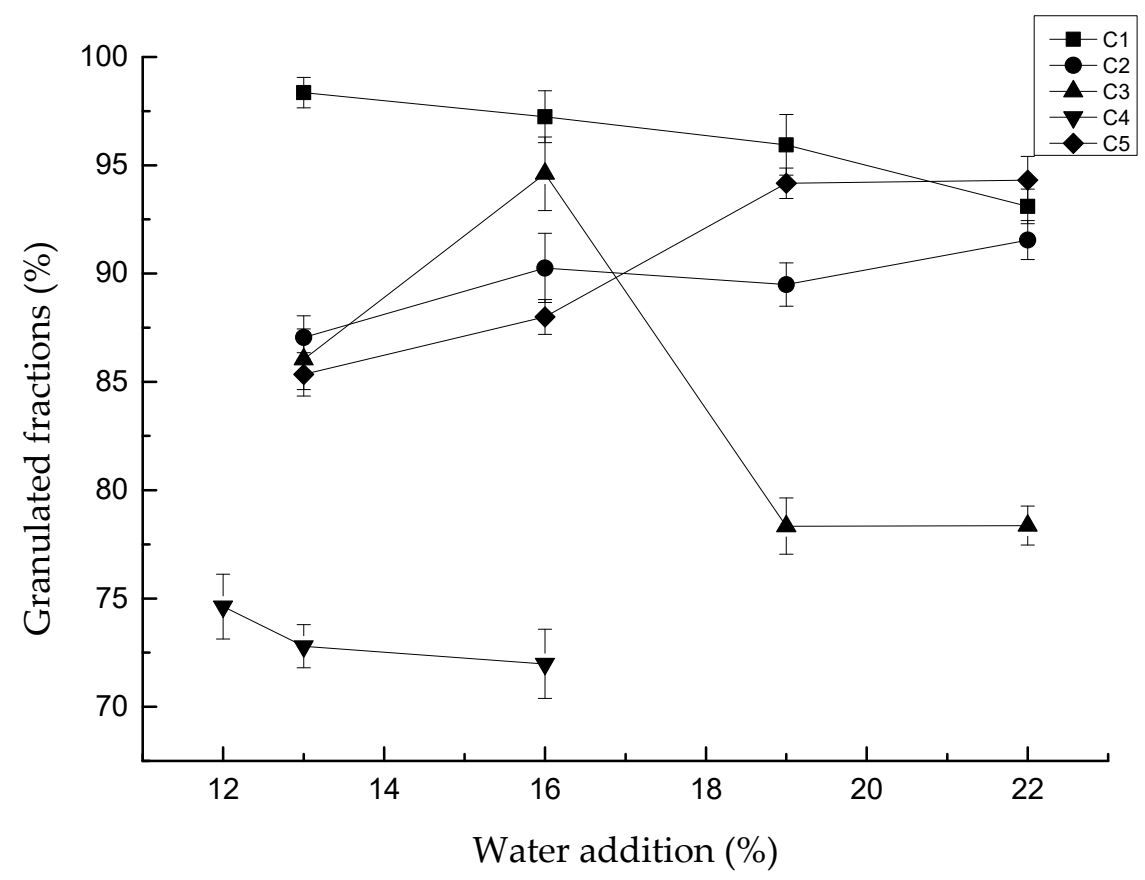

Figure 5. Effect of water addition on granulation (rotation speed is $45 \mathrm{r} / \mathrm{min}$ ). 
Repeated experiments with the same parameters showed that, although the granulation size distribution was not the same every time, the difference in the fraction granulated was not big, and the tendency of forming a bigger particle was the same. This provided the basis for subsequent analysis.

The results also indicated that the effect of water addition on the granulated fraction had discrepancies with different clays. The granulated fraction of $\mathrm{C} 1$ decreased slightly with the increase in water content, and the highest granulated fraction was $98.35 \%$ with water addition of $13 \%$. C2 and C5 granulated fractions increased slightly with the increase in water content, with the highest granulated fraction being $91.55 \%$ and $94.17 \%$, respectively, with water addition of $22 \%$. The granulated fraction of clay in $\mathrm{C} 3$ and $\mathrm{C} 4$ differed greatly with changes in water content.

The influence of rotation speed on the granulated fraction is shown in Figure 6. In general, the granulated fraction first increased and then decreased as the rotation speed increased. However, the regularity was not obvious with different clays. The granulated fraction was the highest when the disc speed was $45 \mathrm{r} / \mathrm{min}$ in $\mathrm{C} 2, \mathrm{C} 4$, and $\mathrm{C} 5$. The granulated fraction in $\mathrm{C} 1$ was the highest at $47 \mathrm{r} / \mathrm{min}$, while it was the highest at $43 \mathrm{r} / \mathrm{min}$ in $\mathrm{C} 3$. The results also showed that the curves of the granulated fraction of different clays seldom intersected. This meant that, compared with the clay properties, the rotation speed had little influence on the granulated fraction.

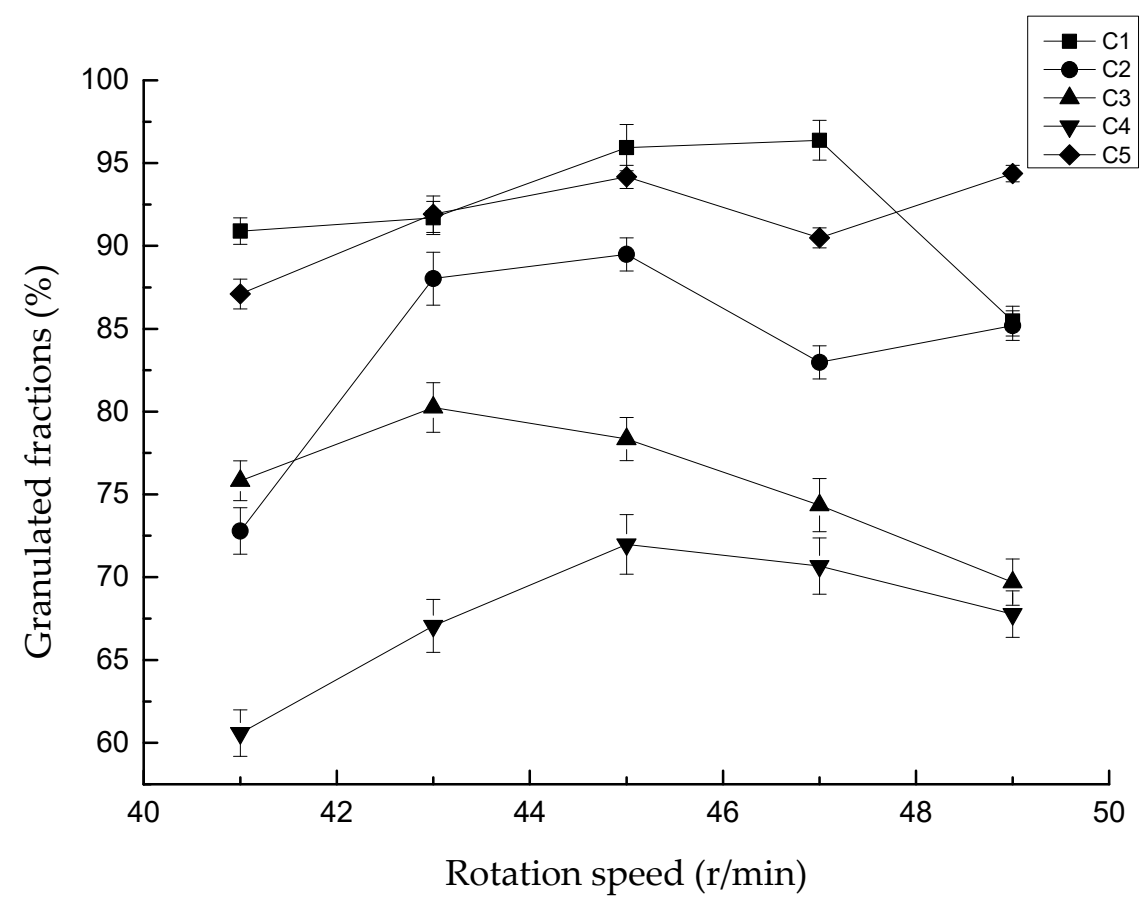

Figure 6. Effect of rotation speed on granulation (water addition is 13\%).

The relationship between water addition, rotation speed, and granulated fraction showed that the process parameters had an influence on the granulation results. Each clay had its own optimum granulation process, and in general, the effect of water addition on the granulated fraction was greater than rotation speed. However, the effect of the process parameters was completely different in different clays. Therefore, the process parameters for one kind of clay cannot be applied to the other. In industrial production, more suitable and generally applicable laws need to be found.

\subsection{Significance Analysis of Different Factors Affecting Granulation}

The granulation of clay is not only influenced by the process parameter but also by its chemical composition, mineral composition, powder property, etc. In order to further understand which factors affect the granulation process of different clays, a significance analysis was carried out. 
Different variables were inputted into SPSS software to analyze the influence of changes in these factors on the granulated fraction. Besides water addition and rotation speed, the VMD, the chemical content, mineral phase content, reduction ratio, angle of repose, and collapse angle of the different clays were put into the analysis, and the significance analysis results are shown in Table 6 (the weak correlation factor has already been removed from the table).

Table 6. Significance analysis results of different properties of clay.

\begin{tabular}{ccc}
\hline & Properties & \multicolumn{2}{c}{ Significance Analysis Results } \\
\hline \multirow{2}{*}{ VMD } & Pearson correlation & $-0.488^{* *}$ \\
\cline { 2 - 3 } & Significance & 0.001 \\
\hline \multirow{2}{*}{ Reduction ratio } & Pearson correlation & $-0.825^{* *}$ \\
\cline { 2 - 3 } & Significance & 0.000 \\
\hline
\end{tabular}

** At the 0.01 level (double tail), the correlation was significant. VMD: volume surface mean diameter.

It can be seen from Table 5 that the VMD and the reduction ratio had the most significant impact on the granulated fraction among all the factors. This means that the granulated fraction can be controlled and optimized by controlling the VMD and the reduction ratio in the granulation process.

The influence of VMD on the granulated fraction with different process parameters and clays was analyzed, and the results are shown in Figure 7. It can be seen that no matter which process parameter was used, as the particle size increased, the granulated fraction increased first and then decreased. The upper and lower limits of the granulated fraction were within $10 \%$. The formula between the granulated fraction and the VMD can be fit as follows: $y=37.15+5.33 x-0.13 x^{2} \pm 9$.

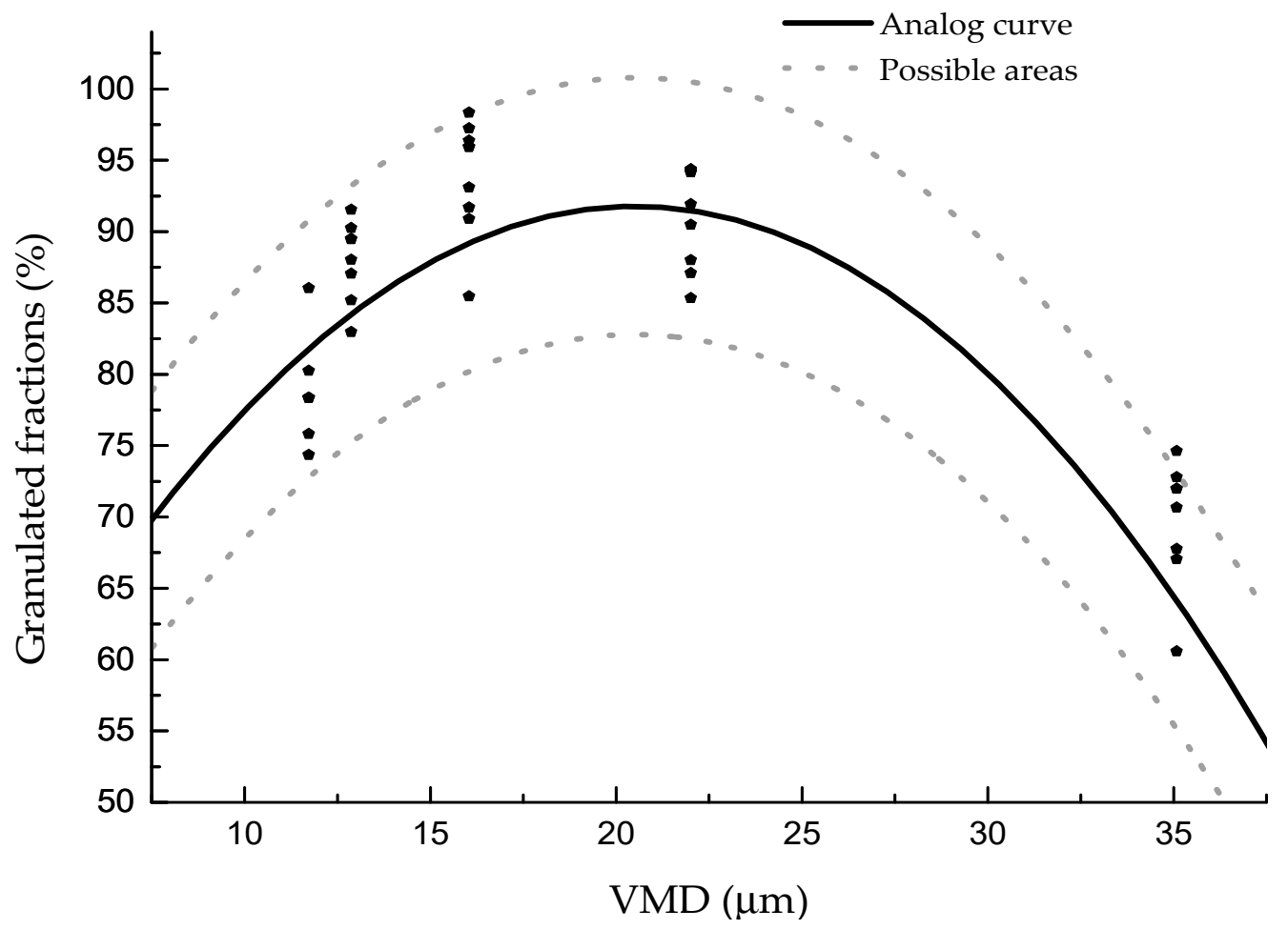

Figure 7. Granulated fraction of different particle sizes with different clays.

Our results were different compared to the general understanding that the smaller the particle, the easier the granulation would be. According to our formulation, clay with a VMD of $20.5 \mu \mathrm{m}$ would be more suitable for disk granulation. This can be explained by the fact that the agglomeration of 
particles in disk granulation occurs mainly through the liquid bridging force, and the adhesion ability of clay particles after adding water is the main factor influencing the granulated fraction. The stronger the adhesion ability, the higher the granulated fraction. Adhesion ability is directly related to the particle size of clay. If the water added is enough to cover the surface of each particle, the larger the surface area, the easier it is to form larger particles. Therefore, with the decrease of VMD, the surface area increases, and the granulated fraction is higher. However, with further reduction of particle size to lower than $20 \mu \mathrm{m}$, the van der Waals force increases significantly, and particles gradually show a stronger adhesion ability [27]. Thus, particles lower than $20 \mu \mathrm{m}$ are easily agglomerated under the action of van der Waals force to produce larger particles, resulting in decreased granulated fraction. Therefore, the granulated fraction first increased and then decreased with the increase of VMD in our experiment.

The influence of the reduction ratio on the granulated fraction with different process parameters and clays was analyzed, and the results are shown in Figure 8. It can be seen that, as the reduction ratio increased, the granulated fraction decreased. Compared with the influence of VMD, the average granulated fraction was nearly linear. The reduction ratio reflects the flowability of the clay particles. As the flowability decreases, it becomes difficult for particles to move, resulting in difficulty in colliding and adhering to each other and causing a reduction of the granulated fraction. Thus, it is better to modify the morphology of clay particles, which will lead to a better result. The fitting formula between the granulation and reduction ratio is as follows: $y=-11 x+574.27 \pm 9$.

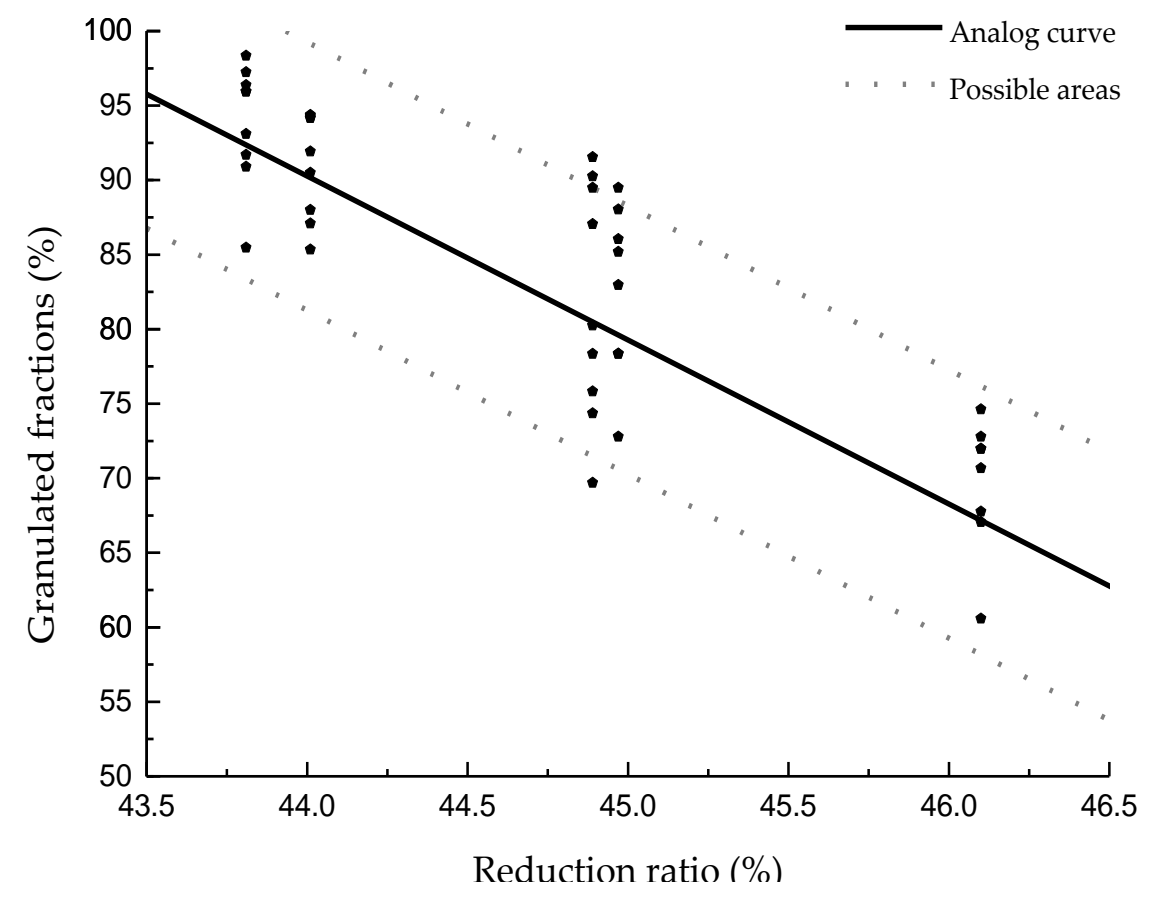

Figure 8. Granulated fraction of different reduction ratio compressibility with different clays.

\subsection{Validation Experiment of the Influence of VMD and Reduction Ratio on the Granulation Process}

In this study, in order to confirm that the curve drawn and the fitting formula are in agreement with the actual results, three groups of new clays were selected to verify the results. The new relationship between the VMD and the granulated fraction is shown in Figure 9, while the relationship between the reduction ratio and the granulated fraction is shown in Figure 10. 


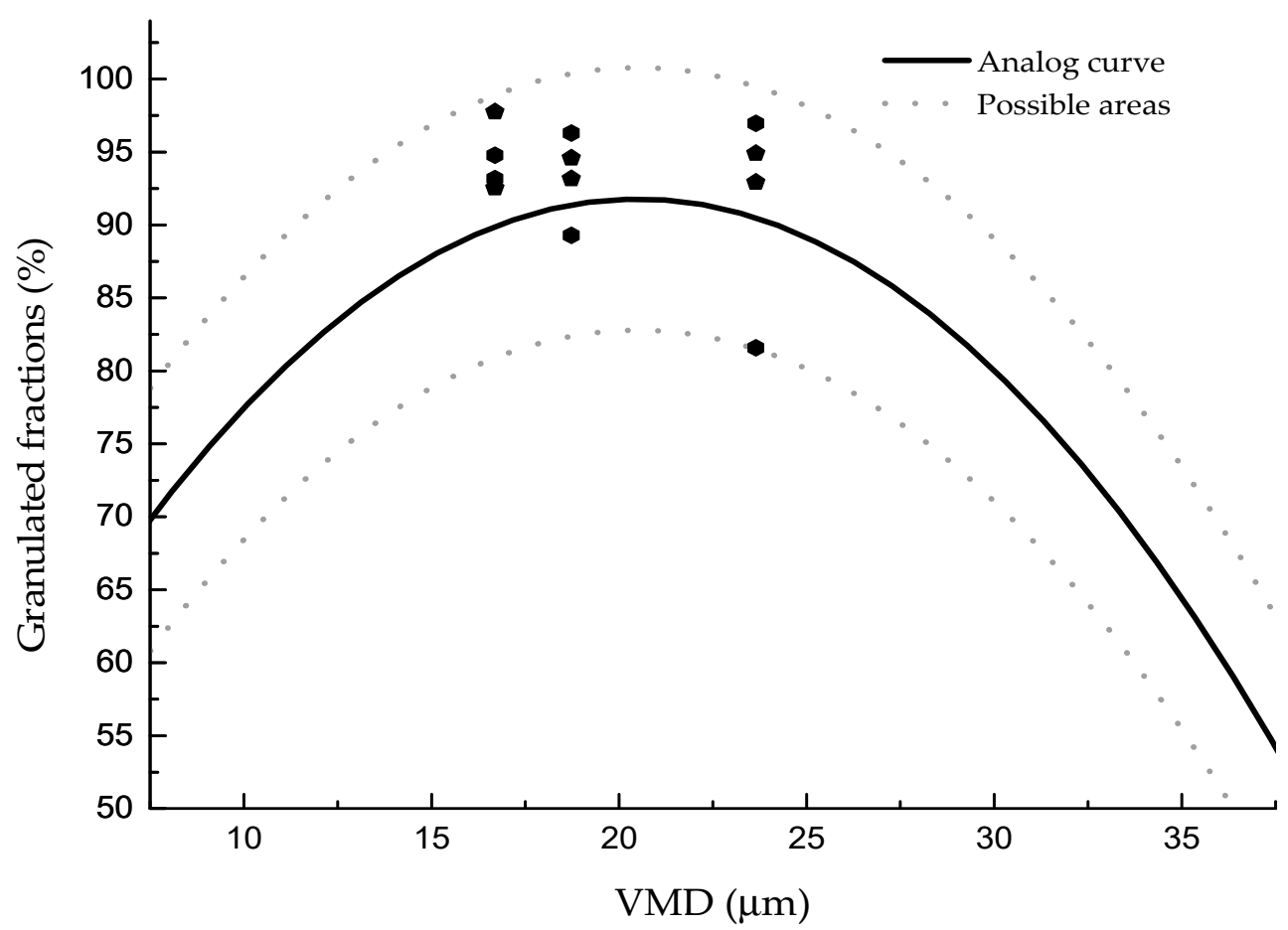

Figure 9. The VMD verification results. (The clays were used for granulation at a rotation speed of $45 \mathrm{r} / \mathrm{min}$ with water addition of $13 \%, 16 \%, 19 \%$, and $22 \%$.)

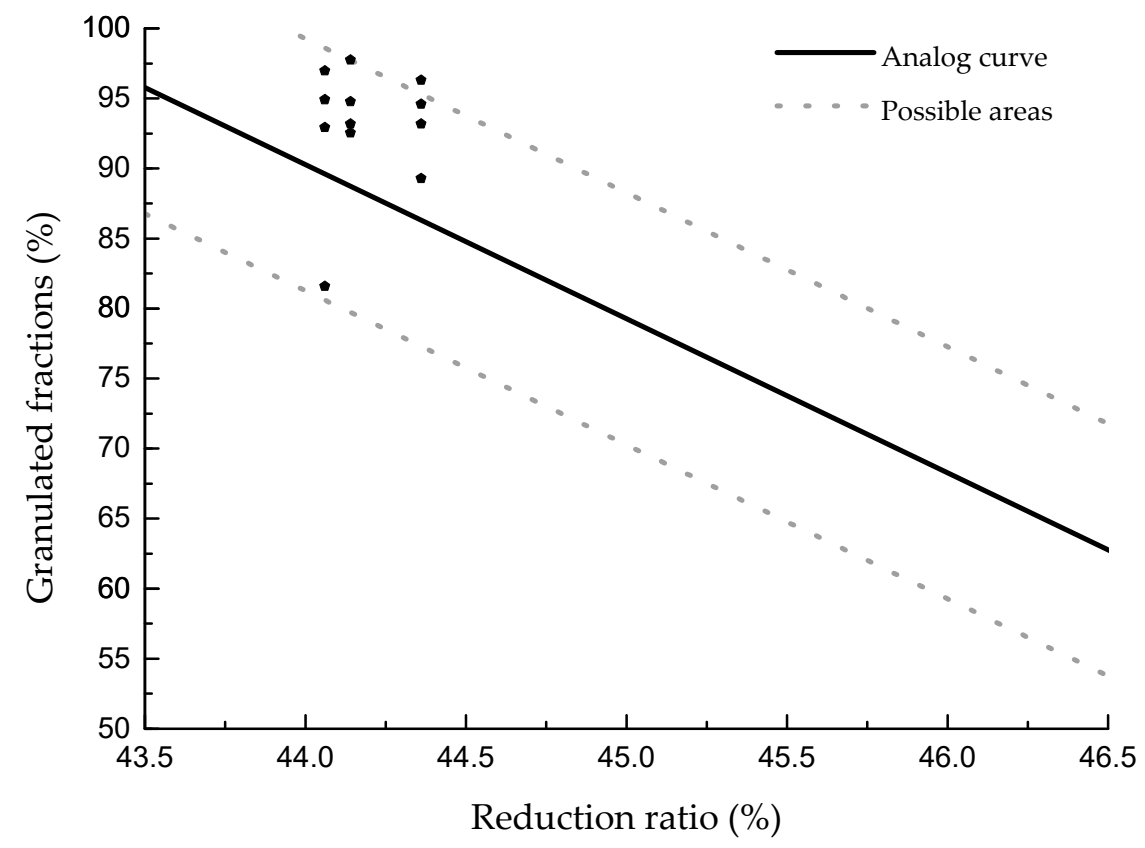

Figure 10. The reduction ratio verification results. (The clays were used for granulation at a rotation speed of $45 \mathrm{r} / \mathrm{min}$ with water addition of $13 \%, 16 \%, 19 \%$, and $22 \%$.)

From Figure 9, it can be seen that the relationship between the granulated fraction and the VMD of different clays is in agreement with the previously summarized regulation, and the highest granulated fraction is slightly higher than what was previously predicted. According to the newly added data, the formula can be modified to $y=37.35+5.35 x-0.13 x^{2} \pm 9$, as shown in Figure 11. In the figure, $95 \%$ of the results are within the formula area. Figure 12 shows the same results as Figure 10; the reduction ratios of the new clays are also in agreement with the previous regulation. Furthermore, by adding the new data, the formula can be modified to $y=-10.7 x+563.82 \pm 9$, as shown in Figure 12 . 


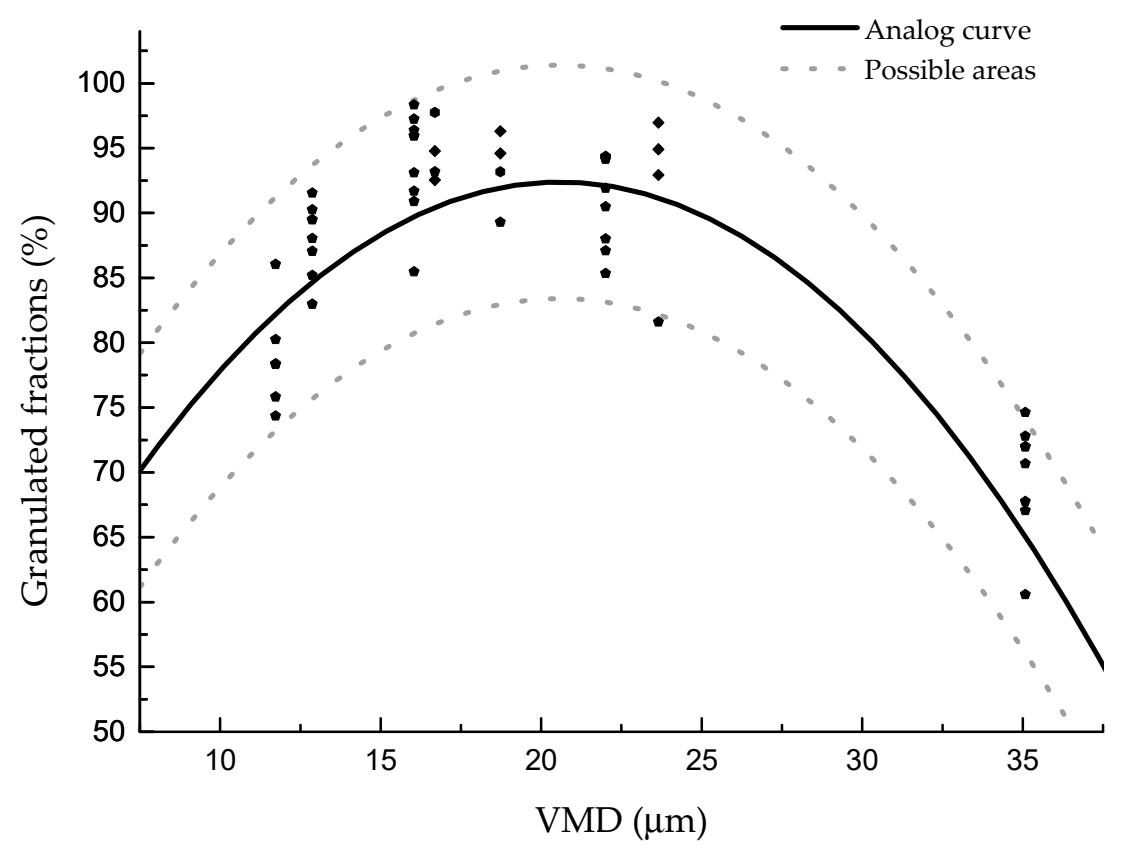

Figure 11. The relationship between the VMD and the granulated fraction.

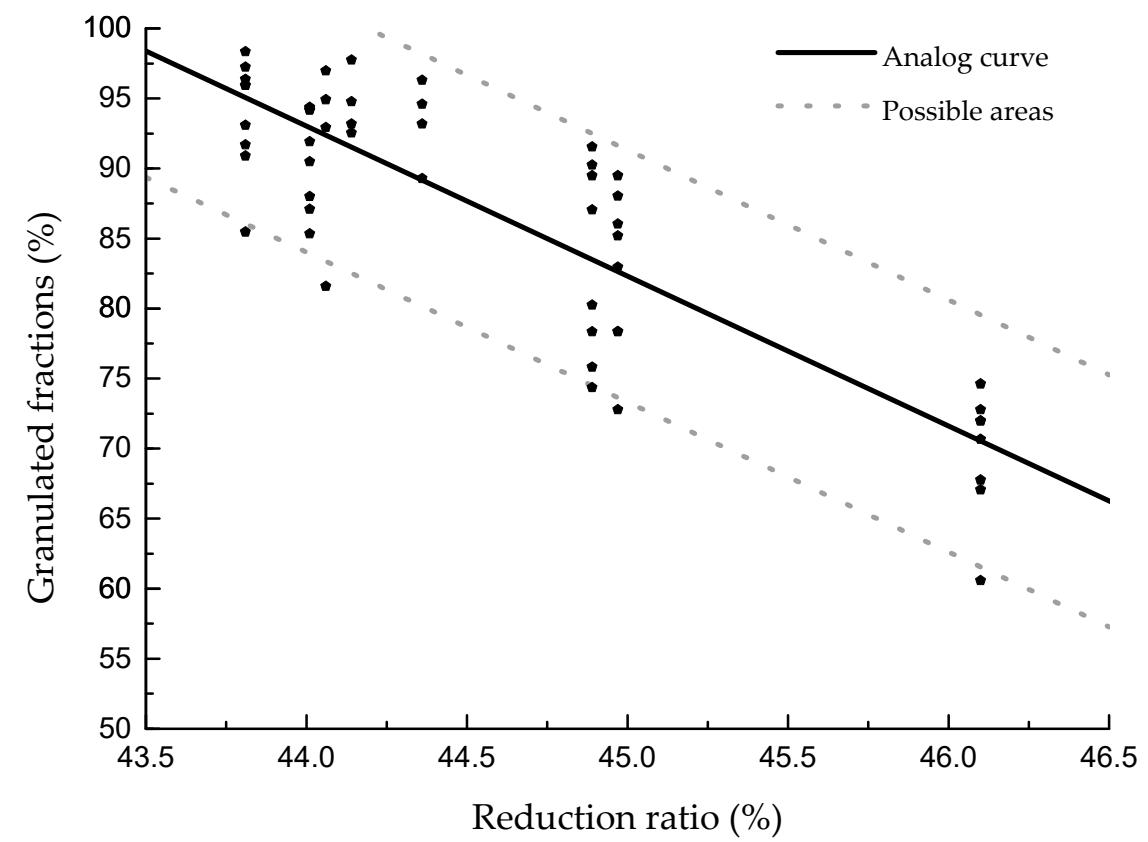

Figure 12. The relationship between the reduction ratio and the granulated fraction.

The formulas of the VMD, the reduction ratio, and the granulated fraction are much more suitable and are generally applicable laws for the granulation process. They can be used for predicting the granulation effect of different clays because particle size and powder properties are relatively easy to measure. They can also be used to determine the best grinding time for raw material, which can be used to guide the actual production process. If the raw material particle size is closer to the optimal particle size from the beginning of the pretreatment stage, the production efficiency will be improved. 


\section{Conclusions}

In this work, clays from different regions were used to study their differences in the disc granulation process. The influence of rotation speed and water addition on the granulated fraction were investigated. The results showed the following:

(1) The granulation performances of clay from different places were totally different. Each clay had its own optimum granulation process. The study of the clay granulation process is not representative and cannot be used to guide production.

(2) Significance analysis showed that the VMD and the reduction ratio had the most significant impact on the granulated fraction among all the factors. No matter which process parameter was used, as the particle size increased, the granulated fraction increased first and then decreased, and the best result was obtained when the average volume diameter was about $20.5 \mu \mathrm{m}$. Furthermore, as the reduction ratio increased, the granulated fraction decreased.

In this study, only eight different clays were used for the experiment. Thus, in the future, research should include more types of clay from different places as well as other materials; for example, industrial solid waste should be studied too. It is hoped that more rules in granulation will be found to guide the actual production process.

Author Contributions: H.L. contributed to the conception of the study, performed the data analyses; J.Z. performed the experiments and wrote the manuscript; W.Z. designed and performed the experiments, contributed significantly to data analysis and manuscript reviewing; T.C. and Y.Y. performed the experiments and Y.Y. contributed to the conception of the study. All authors have read and agreed to the published version of the manuscript.

Funding: This research was funded by the National Key R\&D Program of China (under Contract 2017YFC0703202-2) and the Natural Science Foundation of Shaanxi (under Contract 2019JM-117).

Conflicts of Interest: The authors declare no conflicts of interest.

\section{References}

1. Zhou, D.M.; Hao, X.Z.; Xue, Y.; Cang, L.; Wang, Y.J. Advances in remediation technologies of contaminated soils. Ecol. Environ. Sci. 2004, 13, 234-242.

2. Qian, S.Q.; Liu, Z. An Overview of Development in the Soil-remediation Techniques. Chem. Ind. Eng. Prog. 2000, 19, 10-12.

3. Zhou, Q.X. Technological reforger and prospect of contaminated soil remediation. Tech. Equip. Environ. Poll. Cont. 2002, 8, 36-40.

4. Tampouris, S.; Papassiopi, N.; Paspaliaris, I. Removal of contaminant metals from fine grained soils, using agglomeration, chloride solutions and pile leaching techniques. J. Hazard. Mater. 2001, 84, 297-319. [CrossRef]

5. Ouyang, X.; Chen, J.W.; Zhang, X.G. Advance in supercritical $\mathrm{CO}_{2}$ fluid extraction of contaminants from soil. Geol. Bull. China 2010, 29, 1655-1661.

6. Wang, H.F.; Zhao, B.W.; Xu, J.; Che,H. Technology and research progress on remediation of soils contaminated by heavy metals. Environ. Sci. Manag. 2009, 34, 15-20.

7. Bosecker, K. Microbial leaching in environmental clean-up programmes. Hydrometallurgy 2001, 59, $245-248$. [CrossRef]

8. Dandan, W.; Huixin, L.; Feng, H.; Xia, W. Role of earthworm-straw interactions on phytoremediation of Cu contaminated soil by ryegrass. Acta Ecol. Sin. 2007, 27, 1292-1298. [CrossRef]

9. Yao, Z.; Li, J.; Xie, H.; Yu, C. Review on remediation technologies of soil contaminated by heavy metals. Procedia Environ. Sci. 2012, 16, 722-729. [CrossRef]

10. Han, G.Z.; Wang, D.C.; Xie, X.J. Pedotransfer functions for prediction of soil bulk density for major types of soils in China. Acta Pedol. Sin. 2016, 53, 93-102.

11. Yang, Y. Study on the Properties and Direction of Ceramsite Raw Materials. China Non-Metallic Mining Industry Herald. 1997, 4, 14-19.

12. Zheng, X.; Zhang, B. Effect of Pre-Wetted Shale Ceramsite on Strength and Frost-Resistance of Lightweight Aggregate Concrete. Chin. Ceram. Soc. 2005, 33, 758. 
13. Jiang, M.J.; Peng, L.C.; Zhu, H.H.; Lin, Y.X.; Huang, L.J. Macro-and micro-properties of two natural marine clays in China. China Ocean Eng. 2009, 23, 329-334.

14. Liu, S.Y.; Shao, G.H.; Du, Y.J.; Cai, G.J. Depositional and geotechnical properties of marine clays in Lianyungang, China. Eng. Geol. 2011, 121, 66-74. [CrossRef]

15. Wu, C.J.; Ye, G.L.; Sheng, J.R.; Wang, J.H. Depositional history and geotechnical properties of Shanghai clays. In New Frontiers in Engineering Geology and the Environment; Springer: Berlin/Heidelberg, Germany, 2013; pp. 269-273.

16. Ohtsubo, M.; Egashira, K.; Tanaka, H.; Mishima, O. Clay minerals and geotechnical index properties of marine clays in East Asia. Mar. Georesour. Geotechnol. 2002, 20, 223-235. [CrossRef]

17. Gong, Z.T. Classification of Soil Systems in China; Science Press: Beijing, China, 1999.

18. Liu, Z.M.; Zheng, W.K.; Li, H.; Yang, Y.X.; Zhang, J.J. Experimental Study on the Preparation of Ceramsite Raw Ball by Disc Coating. J. Synth. Cryst. 2018, 47, 1248-1253.

19. Wang, B.; Zheng, W.K.; Li, H.; Ding, S.X. Progress of Granulation Process for Ceramic in China. Bull. Chin. Ceram. Soc. 2015, 34, 1312-1319.

20. Yang, Y.X.; Li, H.; Zheng, W.K.; Bai, Y.; Liu, Z.M.; Zhang, J.J. Experimental study on calcining process of secondary coated ceramsite solidified chromium contaminated soil. Sci. Adv. Mater. 2019, 11, 208-214. [CrossRef]

21. Obraniak, A.; Orczykowska, M.; Olejnik, T.P. The effects of viscoelastic properties of the wetting liquid on the kinetics of the disc granulation process. Powder Technol. 2019, 342, 328-334. [CrossRef]

22. Błaszczyk, M.; Heim, A.; Olejnik, T.P. The effect of wetting on the course of the drum granulation. Chem. Process Eng. 2017, 38, 331-342. [CrossRef]

23. Schæfer, T.; Mathiesen, C. Melt pelletization in a high shear mixer. IX. Effects of binder particle size. Int. J. Pharm. 1996, 139, 139-148. [CrossRef]

24. Hounslow, M.J.; Oullion, M.; Reynolds, G.K. Kinetic models for granule nucleation by the immersion mechanism. Powder Technol. 2009, 189, 177-189. [CrossRef]

25. Gluba, T.; Obraniak, A. Nucleation and granule formation during disc granulation process. Physicochem. Probl. Miner. Process. 2012, 48, 113-120.

26. Obraniak, A. Analysis of the phenomenon of nuclei mass transfer during the disc granulation. Przem. Chem. 2017, 96, 241-244.

27. Huang, X.; Liu, Y. Interparticle forces in viscous ramming paste and it's mechanism analysis. Carbon Tech. 2006, 25, 28 . 